\title{
MONETARY VALUATION OF INFORMAL CARE: THE WELL-BEING VALUATION METHOD
}

\author{
BERNARD VAN DEN BERG ${ }^{\mathrm{a}, \mathrm{b}, *}$ and ADA FERRER-I-CARBONELL ${ }^{\mathrm{c}}$ \\ ${ }^{a}$ Centre for Health Economics Research and Evaluation, Faculty of Business, University of Technology, Sydney, Australia \\ ${ }^{\mathrm{b}}$ Institute of Health Sciences, Faculty of Earth and Life Sciences, VU University, Amsterdam, The Netherlands \\ ${ }^{\mathrm{c}}$ Faculty of Economics and Business (SCHOLAR), AIAS \& Tinbergen Institute, University of Amsterdam, The Netherlands
}

\begin{abstract}
SUMMARY
This paper estimates the monetary value of providing informal care by means of a well-being valuation method. This is done by assessing the compensating variation necessary to maintain the same level of well-being after an informal caregiver provides an extra hour of informal care. The informal caregiver's well-being is proxied by the answer to two subjective well-being questions that were posed in a questionnaire answered by 865 Dutch informal caregivers between the end of 2001 and the beginning of 2002. In the econometric analysis, a distinction is made between the care recipients who are and the ones who are not a family member of the informal caregiver. The results indicate that an extra hour of informal care is worth about 9 or 10 Euros. This equals 8 or 9 Euros if the care recipient is a family member and about 7 or 9 Euros if not. When applying the contingent valuation method to the same sample, the value obtained was 10.52 Euros per hour. This paper concludes that the well-being valuation method is a useful complement to the more traditional valuation methods in the health economics literature in general and more particularly for the economic valuation of informal care: it includes all costs and effects associated with providing care from the perspective of the informal caregiver, it is relatively cheap to implement, and it offers an additional possibility to determine the convergent validity of the different monetary valuation methods. Copyright (C) 2007 John Wiley \& Sons, Ltd.
\end{abstract}

Received 16 August 2004; Accepted 20 December 2006

JEL classification: D61; I11; I31

KEY WORDS: informal care; subjective well-being; compensating variation; economic evaluations

\section{INTRODUCTION}

Economic evaluations of interventions in health care should adopt a societal perspective (Drummond et al., 1997; Russell et al., 1996). This implies that everyone affected by the intervention under study should be considered and that all significant outcomes and costs should be counted, valued, and included (Russell et al., 1996). Informal care is a significant part of the total of care provided, especially to care recipients with chronic and terminal diseases (Norton, 2000). Still, the costs of informal care are often ignored in economic evaluations (Stone et al., 2000). This might be due to the lack of valuation methods that are both theoretically valid and empirically feasible (Van den Berg et al., 2004).

The existing literature on the economic valuation of informal care has mainly focused on the costs experienced by the caregivers, which are usually valued in terms of time spent on providing informal care. Two valuation methods are usually recommended and applied: the opportunity cost method and

*Correspondence to: Faculty of Earth and Life Sciences, Institute of Health Sciences, Department of Health Economics \& Health Technology Assessment, VU University, De Boelelaan 1085, 1081 HV Amsterdam, The Netherlands. E-mail: bernard.van.den.berg@falw.vu.nl 
the proxy good method (Drummond et al., 1997; Luce et al., 1996; Posnett and Jan, 1996). ${ }^{1}$ Van den Berg et al. (2004, 2005a-c) present detailed discussions on the disadvantages of both methods. The important shortcoming of these two methods is that they do not fully reflect the preferences of the informal caregiver (care recipient) as welfare economics demands. In the opportunity cost method only the foregone earnings of the informal caregiver are considered, and it ignores thus the (dis)utility that a caregiver might derive from providing the care (Van den Berg et al., 2005b). The proxy good method values informal care at the price of a market substitute, e.g. professional home care. This method assumes that informal care and professional care are perfect substitutes. Nevertheless, this might not be the case. For example, individuals may show a clear preference for one type of care (professional or informal), which is the one they finally choose. The reasons include, the price of professional care, the quality of the professional care, the availability of professional care - waiting lists -, and a feeling of obligation to provide the care themselves (Van den Berg et al., 2004, 2005b). Therefore, valuing informal care at the price of professional care does not reflect either the preferences of the informal caregiver nor those of the care recipient (Van den Berg et al., 2005b). For this reason, Van den Berg et al. $(2004,2005 \mathrm{a}-\mathrm{c})$ call for the development of new methods to value the costs associated with providing informal care. They suggest using stated preference methods, such as contingent valuation or conjoint analysis (also called choice experiments ${ }^{2}$ ), as more adequate to value informal care.

This paper presents an alternative valuation method in which the cost of providing informal care is valued in terms of the loss in well-being suffered by the informal caregiver. This is: the monetary value of informal care is estimated by looking at the necessary income (compensating variation) to maintain the same level of informal caregiver's well-being after providing an additional hour of informal care. This method was first applied in Health Economics by Ferrer-i-Carbonell and Van Praag (2002) to provide a monetary valuation of various illnesses. Later, Van den Berg et al. (2004) suggested applying this method to value informal care. The well-being valuation method has proven to be useful to calculate shadow prices for other non-market commodities, for instance, airport noise (Van Praag and Baarsma, 2005).

By looking at the impact of providing informal care on an individual's well-being, the well-being valuation method captures all the costs (and benefits) suffered (and enjoyed) by the caregiver in terms of own utility, as proxied by self-reported subjective well-being. Therefore, and compared to more traditional methods of valuing informal care, the well-being valuation method values the total costs and benefits of informal care from the perspective of the caregiver. Thus, not only time costs are incorporated, but also financial outlays related to informal care, such as telephone calls or home adaptations, and non-financial aspects, such as physical and mental tiredness associated with providing informal care. These costs are all incorporated to the extent that they affect an individual's subjective well-being.

Next to using a fairly new valuation method to value informal caregiving, the empirical analysis is also innovative on that it distinguishes between two types of caregivers, depending on whether the care recipient is or is not a family member of the caregiver. This translates into two sorts of compensating variation and thus into two values of informal care depending on the relationship between the caregivers and their care recipients.

In what follows, the next section describes the method. This section is divided into four parts: an introduction of the well-being valuation method followed by a comparison with the existing alternatives; a description of the survey questions used; a discussion of the well-being model; and an explanation of the econometric methods. The third section presents the data and descriptive statistics. The fourth section discusses the results for the well-being equation. The fifth section assesses the

\footnotetext{
${ }^{1}$ See, Netten (1990) for an overview and discussion of the costs, other than time, related to informal care.

${ }^{2}$ See Louviere et al. (2000) for a discussion of the differences between conjoint analysis and choice experiments.
} 
monetary value of informal care, while the sixth section compares it with the findings using the contingent valuation method. Finally, the last section concludes and discusses.

\section{THE WELL-BEING VALUATION METHOD APPLIED TO INFORMAL CARE}

\section{Introduction}

The well-being valuation method can be shortly described as follows. First, we estimate the effect of providing informal care and of income on individual's subjective well-being. In a second step, we estimate the necessary income (compensating variation) to maintain the same level of informal caregiver's well-being after providing an additional hour of informal care. This compensating variation is taken as the monetary value of informal care. The well-being valuation method is thus based on the economic standard practice of valuing non-market commodities with shadow prices, which, in the present context, are described as the change in well-being followed by a change in the provision of the commodity informal care.

Without despising the importance of contingent valuation and conjoint analysis, we would like to emphasise the advantages of the well-being valuation method with respect to the other two methods. First, it is often argued that contingent valuation suffers from biases due to strategic behaviour of the respondents (Mitchell and Carson, 1989). This is not a danger when using an indirect valuation method, such as conjoint analysis or the well-being valuation method, in which respondents are not explicitly asked to state a monetary value for the commodity under valuation. Second, contingent valuation and conjoint analysis can be difficult for respondents to answer, as these questions often refer to topics the respondents are not familiar with. In the well-being valuation method, instead, respondents do not have to think about the commodity under valuation, as they are only requested to value their satisfaction with life. In the present questionnaire, all respondents were providing informal care and were therefore familiar with the topic under study. This implies that this shortcoming does not hold in the present context. Actually, Van den Berg et al. (2005b) concluded that being familiar with making choices regarding caregiving might be an explanation for the relative small difference between willingness to pay and willingness to accept (WTA) results found with this sample as opposed to many other contingent valuation studies. Third, the results obtained with contingent valuation and conjoint analysis depend on the format and framing of the question (Boyle et al., 2001; Johannesson and Borgquist, 1991; Johannesson et al., 1993; Roe et al., 1996). There is no evidence regarding format or framing effects in the well-being valuation method so far, and this paper will address this issue in more detail. Fourth, the well-being valuation question is relatively easy to answer for respondents. Easiness of responding a question is not only good in itself (questionnaires are cheaper and respondents might feel less burden and might therefore be more willing to collaborate in further research) but it also reduces biases due to sample selection (lower item non-response or even lower response rates), which may affect the results considerably. It has been shown that the percentage of individuals who do not respond to well-being valuation questions is very low (Van Praag and Ferrer-i-Carbonell, 2004).

The main conceptual difference between the well-being valuation method on the one hand and the contingent valuation and conjoint analysis methods on the other hand is the underlying concept of utility. The well-being valuation method derives individual's valuation from their experienced utility, i.e. the satisfaction they derive from the current situation. Contrarily, the other two valuation methods are based on hypothetical answers and, as such, capture an individual's utility from a situation they may not be experiencing (for a detailed discussion, see Ferrer-i-Carbonell et al., 2006).

Regarding the data collection and the posterior statistical analysis, there are not many relevant differences between contingent valuation, conjoint analysis and the well-being valuation method. In the literature, there are various statistical-econometric methods recommended to analyse the different types 


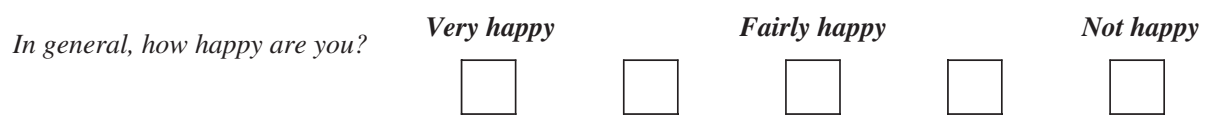

Figure 1. Happiness question, scale 1-5 (question 1)

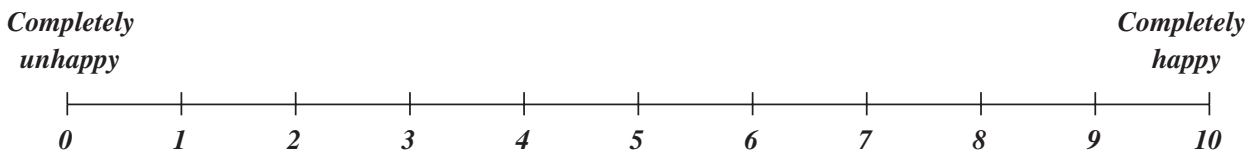

Figure 2. Happiness question, scale 0-10 (question 2)

of valuation questions. The choice of one or another depends on the way the questions are framed and the assumptions one is willing to make, for instance, regarding the measurement level of the answers.

\section{Survey questions}

Here, we describe the three (groups of) questions that are most important for the present study. These are: (1) the questions related to the informal care provided; (2) two measures of well-being, and (3) household income.

In the survey, informal caregivers are asked how much time they spent on providing informal care in the week preceding the interview. Van den Berg and Spauwen (2006) give a detailed discussion of the validity of this approach. Additionally, the questionnaire includes a question on the social relationship between the informal caregivers and their care recipients. This allows us to distinguish between hours of informal care provided to a family member and those provided to a non-family member. Family members are partners, parents, children, sisters, and brothers. Non-family members are friends, neighbours, and in-laws of the informal caregiver.

The survey includes two questions in which informal caregivers are asked to indicate their own wellbeing by placing a cross in or on a visual analogue scale. The answer to these (or similar) questions are usually referred to as an individual subjective well-being. ${ }^{3}$ The two questions in the survey are phrased as shown in Figures 1 and 2.

Even though both questions aim at measuring the same concept, i.e. individual's subjective wellbeing, there are some differences between both questions. The main difference is their place in the questionnaire. Question 1 (Figure 1) was included in the same section as the socio-economic questions, while question 2 (Figure 2) was included in the same section as the questions about the provision of informal care. This was done so as to examine whether the effect of hours of provided informal care on individual's subjective well-being was different depending on where the question was asked. One could imagine that individuals would be more aware of their informal care activities when answering question 2 and could therefore give a different answer than in question 1. There are three other important differences between the two questions. These differences were also introduced so as to check for consistency. They are: (1) the number of values (5 versus 11); (2) the categories offered to the respondent (verbal versus numerical); and (3) the order (starting for very happy versus starting for very unhappy).

\footnotetext{
${ }^{3}$ The subjective well-being literature uses as interchangeable the terms well-being, happiness, and satisfaction with life (Blanchflower and Oswald, 2004; DiTella et al., 2001; Frey and Stutzer, 1999). The term used is often chosen independently of the exact formulation used in the questionnaire itself. Here, we will use the term well-being, although we will refer to the question as the happiness question, because we asked caregivers for their happiness.
} 


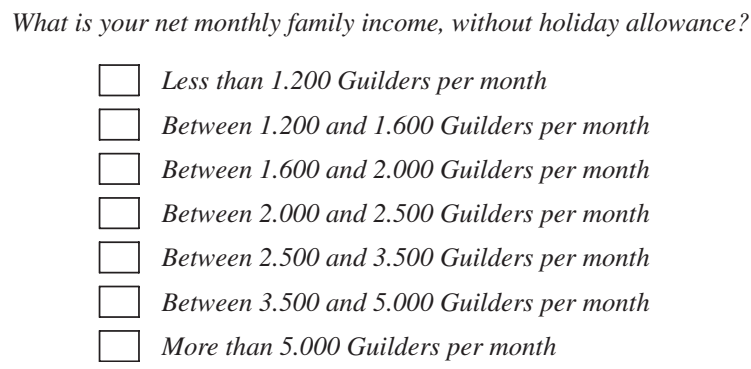

Figure 3. Income question

The empirical analysis estimates the value of informal care by using both questions (see section 'A monetary value of informal care'). By using both questions, we are able to check for consistency between the answers to the two well-being questions. In section 'The well-being of informal caregivers: empirical findings', we will show the results and conclude that both questions seem to carry the same type of information regarding caregivers' well-being.

The third piece of information necessary to estimate the compensating variation of providing an extra hour of informal care is the income of the informal caregiver. The income question in the survey is given in Figure 3.

The income question is asked in intervals. In order to valuate informal care in monetary terms, however, income is needed on a continuous scale (see section 'A monetary value of informal care'). As a good approximation the mean of the interval is taken as the income of the respondent. Given that the intervals are fairly small (a Guilder is equivalent to about 0.45 Euros), this question provides a very good approximation of the actual income. For individuals in the lowest and highest category, household income was set at 800 and 7500 Guilders, respectively. ${ }^{4}$ Obviously, the imputed income for these two groups of individuals has the largest error. Nevertheless, only $19 \%$ of individuals indicated to have an income in one of these two categories: about $2.3 \%$ in the lowest and $16.7 \%$ in the highest category. In addition, we examined how sensitive our results were to the choice of these two income amounts. First, we compared our figures with the net family income in the Netherlands according to Statistics Netherlands (CBS, 2006). Based on this comparison, we chose different income levels as the bottom and top categories and proceed to do sensitivity analysis. Second, we performed sensitivity analysis using the amounts stated in the questionnaire for the bottom and top category. In the present case this means using 1200 guilders for individuals in the bottom income category and 5000 guilders for the ones on the top income category. The results indicated that the choice of income level did not influence the results.

\section{The well-being model}

Subjective questions on self-reported well-being have been used in economics to understand and explore a large range of interesting topics, such as unemployment, health, job situation, and income (Blanchflower and Oswald, 2004; Clark and Oswald, 1994; DiTella et al., 2001; Easterlin, 2001; Ferreri-Carbonell, 2005; Ferrer-i-Carbonell and Frijters, 2004; Ferrer-i-Carbonell and Van Praag, 2002; Frey and Stutzer, 2002; Frijters et al., 2004; Oswald, 1997; Van Praag and Ferrer-i-Carbonell, 2004). In doing so, economists take individuals answer to well-being questions as a proxy to measure utility (see, e.g. Frey and Stutzer, 2002; Luttmer, 2005). In other words, one of the main assumptions in the well-being

\footnotetext{
${ }^{4}$ An alternative method is to estimate an income equation. However, this option was discarded, as the data set does not contain sufficient information (explanatory variables) to explain income.
} 
literature is that the answer to the well-being question is a monotonic positive transformation of the theoretical concept we are interested in (Ferrer-i-Carbonell and Frijters, 2004).

The first step of the present valuation method is to explain the well-being of the informal caregiver ( $W_{\text {ic }}$ ) by a set of objective variables. The following model is used to estimate $W_{\text {ic }}$ :

$$
W_{\text {ic }}=W\left(y, H_{\text {ic }}, x\right)
$$

where $y$ denotes the net family income, $H_{\mathrm{ic}}$ represents the hours of provided informal care per week, and $x$ is a vector of individual socio-economic and demographic variables. The vector $x$ includes: gender; age; marital status; having children; level of education; whether the individual is unemployed; whether the caregiver has an illness; and a set of dummy variables indicating whether the care recipient has mental or physical problems. Selection of variables is based on their expected direct effect on well-being, previous knowledge (existing literature in economics as well as psychology and sociology), theoretical insights, intuition, and data availability.

Equation (1) postulates that informal caregivers' well-being depends, among other things, on income and on hours of provided informal care. The relationship between income and well-being is expected to be positive, while the relation between hours of provided informal care and well-being is expected to be negative. The hypothesised negative relationship is mainly due to the opportunity cost of time of providing care and the involved negative subjective psychological and physical burden of providing care (Kramer, 1997). It is also possible that providing care has two positive effects on the caregiver's wellbeing. First, caregivers may provide care because they expect that it has a positive effect on the care recipient's health and therefore has a positive effect on their own well-being due to the interdependence of their utility functions (Van den Berg et al., 2005b). Second, the caregivers may derive positive utility from the process of caring itself, for example, due to increases of their self-esteem. This is called process utility or direct utility. For a proxy measure of process utility via the subjective burden literature, see (Jacobi et al., 2003). In an empirical study using almost ${ }^{5}$ the same sample as the present paper, Brouwer et al. (2005) show that about half of the caregivers derive positive utility form providing the care themselves instead of the hypothetical scenario of handing the care over to another (selfchosen) person.

In the present paper, we are interested in the total effect of providing informal care on caregiver's well-being, as our results are aimed to be used in economic valuations. Therefore, the positive and negative effects that providing informal care may have on the caregiver's well-being are not separately estimated. Although the total effect is expected to be negative, it may well be that, for some individuals, the relationship is positive.

From Equation (1) one can derive the existing trade-off between income and hours of informal care provided that maintain well-being unchanged. This trade-off is taken as the monetary value of providing an extra hour of informal care. In micro-econometric terms: the monetary value of informal care is obtained by calculating the compensating variation $(\Delta y)$ necessary to maintain informal caregivers' well-being $\left(W_{\text {ic }}\right)$ constant after increasing the amount of informal care provided $\left(\Delta H_{\text {ic }}\right)$. Formally, this is written as

$$
\delta y / \delta H_{\mathrm{ic}}=-\frac{\delta W_{\mathrm{ic}} / \delta H_{\mathrm{ic}}}{\delta W_{\mathrm{ic}} / \delta y}
$$

(For a theoretical discussion of this method, see Ferrer-i-Carbonell and Van Praag, 2002.)

Equation (1) is extended so as to allow the (negative) effect of providing informal care to depend on the (non-)family relationship between the caregiver and the care recipient. In the present sample, about $88 \%$ of the informal caregivers provide care to a family member (partner, parent, children, sister, or

\footnotetext{
${ }^{5}$ The cited study also included the results of a pilot study and therefore included 950 informal caregivers instead of the 865 informal caregivers of the present study.
} 
brother). Previous research has shown that providing informal care to close family members involves a relatively larger negative subjective burden (both physically and emotionally) than providing care to non-family members (Hughes et al., 1999; Kramer, 1997). If this evidence is confirmed, a stronger inverse relationship between hours of provided informal care and well-being will be found for informal caregivers who are family of the care recipients than for informal caregivers who are not.

\section{Econometric methods}

The two measures of well-being provide different types of answers and thus will be regressed by a different method. In the subjective well-being literature, models of the type presented in Equation (1) have been regressed with linear as well as with latent variable econometric techniques. The first ones assume that the answers to well-being questions are cardinal, while the second type of techniques only assume ordinality. Ferrer-i-Carbonell and Frijters (2004) show that assuming cardinality or ordinality generates similar results in terms of the trade-offs between variables, which is the information we use in this paper. The first measure of well-being (see Figure 1 in section 'Survey questions') is regressed by means of an ordered probit (OP). This captures the fact that the answers can only take five discrete values and hence do not give the exact level of well-being but the range in which it lies. Moreover, using an OP model implies that the answers to the happiness question are taken to be interpersonally comparable at an ordinal level, e.g. an individual answering a 4 is happier than one answering a 2 but not necessarily twice as happy.

Surprisingly, a significant number of caregivers answered the second well-being question (see section 'Survey questions') by placing a cross at any point of the 0-10 line (instead of only at the integer numbers, which were marked with a short line - see Figure 2). The coding of the answers took this into account by rounding the answer to one decimal number. Thus, the happiness question can take 101 values. Therefore, the OP is not a logical method to use. Instead, we use ordinary least-squares (OLS) regression. ${ }^{6}$

The model to be econometrically estimated by OP is:

$$
\begin{aligned}
& W_{\mathrm{ic}}^{*}=\alpha+\beta \operatorname{Ln}(y)+\gamma \operatorname{Ln}\left(H_{\mathrm{ic}}\right)+\varphi\left(\operatorname{Ln}\left(H_{\mathrm{ic}}\right) * \mathrm{NF}\right)+\delta x+\varepsilon \\
& W_{\mathrm{ic}}=k \leftrightarrow \mu_{k} \leq W^{*}<\mu_{k+1}
\end{aligned}
$$

where $W_{\text {ic }}^{*}$ is the unobserved latent variable, $W_{\text {ic }}$ is the observed (self-reported) well-being, $k$ are the five discrete categories (1-5), and $\mu_{k}$ are the six intercept terms, where $\mu_{1}=-\infty, \mu_{6}=\infty$, and the other four intercept terms are estimated (Maddala, 1983). The term NF is a dummy variable that equals 1 if the informal caregiver and the care recipient are not family related, and $\varepsilon$ represents the unobservable error term. The specification for the OLS estimation is similar to the one presented in Equation (3). The only difference is that there is no latent variable involved.

Equation (3) shows that the household income and the provided number of hours of informal care are taken in logarithms. The logarithmic relationship between income and well-being captures the usual assumption of diminishing marginal utility of income. The diminishing marginal utility relationship is also postulated for hours of provided care. These non-linear relationships imply that the value of an extra hour of informal care will depend on the current respondent's income and number of provided hours of care. Although at odds with the theory of diminishing marginal utility of leisure, the logarithmic specification for hours of informal care is introduced so as to deal with caregivers who over report their hours. In our sample we have many family-related caregivers who report a high number hours of care, which is probably due to over reporting (see section 'Data' for details).

\footnotetext{
${ }^{6}$ We have also run the question in Figure 1 with OLS (instead of OP) and the question in Figure 2 with OP (instead of OLS). Doing that has led to similar results.
} 
By rewriting Equation (2) for the specification presented in Equation (3), the monetary value of providing an extra hour of informal care to a family member can be written as

$$
\% \Delta y=\exp \left(\frac{\gamma}{\beta} \delta \ln H_{\text {ic }}\right)-1
$$

and, if the care recipient is not a family member, as

$$
\left.\% \Delta y=\exp \left(\frac{\gamma+\varphi}{\beta} \delta \ln H_{\text {ic }}\right)\right)-1
$$

where $\% \Delta y$ is the percentage of monthly income increase necessary to compensate for an increase of $\delta \ln H_{\text {ic }}$ hours of care a week.

\section{DATA}

The data used in the empirical analysis were collected with the help of the Dutch regional support centres for informal caregivers between the end of 2001 and the beginning of 2002. Fifty-nine regional centres were approached and 40 of those finally participated in the research. Through these centres, 3258 postal surveys were sent to informal caregivers. The final sample consisted of 865 informal caregivers, which amounts to a response rate of $26.6 \%$. The main objective of this survey was to collect the necessary information to value informal care (Van den Berg, 2005) by using three different methods, namely contingent valuation (Van den Berg et al., 2005b), conjoint analysis (Van den Berg B, Al MJ, Van Exel JAJ, Koopmanschap MA, Brouwer WBF. 2006. Economic valuation of informal care: conjoint analysis applied in a heterogeneous population informal caregivers. Submitted.), and the well-being valuation method.

Table I presents descriptive statistics for all the caregivers (columns two and three). Additionally, descriptive statistics are presented for the two sub-samples of interest, namely those who are family related to their care recipients and those who are not. Finally, the last column shows whether these two samples are statistically different on the variables we are interested on. We tested for statistical differences in scores of family members versus non-family members by means of a two-sided $t$-test in case of continuous variables and by means of a chi-squared test in case of categorical variables. In all cases, a $p$-value below 0.05 implies that there is a statistically significant difference between family and non-family members at the $5 \%$ level.

The mean reported well-being is very similar for both well-being questions. ${ }^{7}$ Compared to two of the most used western data sets on the well-being literature, namely the British Household Panel Survey (BHPS) and the German Socio-Economic Panel (GSOEP), the present sample scores rather low in terms of subjective well-being. For example, in 2002 the average reported well-being in the GSOEP was about 7 on a $0-10$ scale. Caregivers who take care of a family member report a statistically significant lower well-being than those who care for a non-family member.

The majority of the informal caregivers $(88 \%)$ are family of the care recipient. On average, the informal caregivers in the sample provide many hours (49 a week) of care, which is more than the average for the Netherlands as a whole (26.8 a week by primary caregivers) (Timmermans, 2003). The average of provided care hours, however, differs between the two sub-samples. While for family members this average is about $51 \mathrm{~h}$ a week, for non-family members this is about 30 . This difference could be due to over reporting of the hours family members put into caring. The reason is that familyrelated individuals may count as informal care activities the things that they would do for their family (e.g. partner) regardless of whether they are sick or not, for example, cooking, see, e.g. Van den Berg and Spauwen (2006) and Van den Berg et al. (2006). ${ }^{8}$ Nevertheless, it is still probable that family

\footnotetext{
${ }^{7}$ Comparing the means of two well-being questions implicitly assumes cardinality of well-being. Presenting this statistic helps to understand the data.

${ }^{8}$ The logarithmic specification for hours of informal care partly corrects for this.
} 
Table I. Descriptive statistics $(n=865)$

\begin{tabular}{|c|c|c|c|c|c|c|c|}
\hline & \multicolumn{2}{|c|}{ All } & \multicolumn{2}{|c|}{ Family } & \multicolumn{2}{|c|}{ Non-family } & \multirow{2}{*}{$\begin{array}{l}\text { Difference } \\
p \text {-value }\end{array}$} \\
\hline & Mean & $\begin{array}{l}\text { Standard } \\
\text { deviation }\end{array}$ & Mean & $\begin{array}{l}\text { Standard } \\
\text { deviation }\end{array}$ & Mean & $\begin{array}{l}\text { Standard } \\
\text { deviation }\end{array}$ & \\
\hline $\begin{array}{l}\text { Well-being } \\
(1=\text { not happy to } 5=\text { very happy })\end{array}$ & 2.846 & 1.151 & 2.787 & 1.139 & 3.305 & 1.149 & 0.0000 \\
\hline $\begin{array}{l}\text { Well-being } \\
(0=\text { completely unhappy to } \\
10=\text { completely happy })\end{array}$ & 5.713 & 2.182 & 5.625 & 2.160 & 6.406 & 2.240 & 0.0010 \\
\hline Hours informal care per week & 48.998 & 52.489 & 51.595 & 53.730 & 30.226 & 37.664 & 0.0004 \\
\hline $\begin{array}{l}\text { Care recipient is not a } \\
\text { family member }\end{array}$ & 0.116 & 0.320 & & & & & \\
\hline $\begin{array}{l}\text { Net monthly household } \\
\text { income (Euros) }\end{array}$ & 1665 & 883 & 1685 & 889 & 1513 & 824 & 0.0779 \\
\hline Caregiver is a male & 0.234 & 0.423 & 0.244 & 0.430 & 0.150 & 0.359 & 0.0360 \\
\hline Age caregiver & 60.207 & 12.066 & 60.440 & 12.120 & 58.419 & 11.544 & 0.1171 \\
\hline Caregiver is married & 0.763 & 0.425 & 0.776 & 0.417 & 0.660 & 0.476 & 0.0100 \\
\hline Caregiver has children & 0.812 & 0.391 & 0.818 & 0.386 & 0.760 & 0.429 & 0.1610 \\
\hline Caregiver education: low & 0.385 & 0.487 & 0.377 & 0.485 & 0.439 & 0.499 & 0.2410 \\
\hline Caregiver education: middle & 0.454 & 0.498 & 0.450 & 0.499 & 0.480 & 0.502 & 0.5840 \\
\hline Caregiver education: high & 0.162 & 0.368 & 0.172 & 0.377 & 0.082 & 0.275 & 0.0220 \\
\hline Caregiver is unemployed & 0.015 & 0.122 & 0.013 & 0.114 & 0.030 & 0.171 & 0.1910 \\
\hline Caregiver has an illness & 0.747 & 0.435 & 0.756 & 0.430 & 0.680 & 0.469 & 0.1910 \\
\hline $\begin{array}{l}\text { Care recipient has mental } \\
\text { problems }\end{array}$ & 0.186 & 0.389 & 0.181 & 0.385 & 0.226 & 0.420 & 0.2900 \\
\hline $\begin{array}{l}\text { Care recipient has physical } \\
\text { and mental problems }\end{array}$ & 0.310 & 0.463 & 0.312 & 0.464 & 0.290 & 0.456 & 0.6680 \\
\hline $\begin{array}{l}\text { Care recipient has physical } \\
\text { problems }\end{array}$ & 0.505 & 0.500 & 0.507 & 0.500 & 0.484 & 0.502 & 0.6700 \\
\hline
\end{tabular}

members provide, on average, more hours of informal care. The vast majority of informal caregivers are married, are women, and have children. Only $1.5 \%$ of the sample is unemployed, viz. they do not have a paid job nor are they looking for it. It is important to keep in mind that many of the respondents are already retired $(21.7 \%)$. The mean monthly household income is fairly low. It is just over 1600 Euro net of taxes per month, while the Dutch average in 2002 was about 2350 Euro (CBS, 2006). A possible explanation is that the respondents in this sample are relatively old, with $35 \%$ being above the official retirement age (65 years). Moreover, the large amount of time spent on providing informal care may hamper having a (full-time) paid job. A large majority of the caregivers report having one or more illnesses themselves. They care for people with physical problems $(50 \%)$, physical and mental problems $(31 \%)$ or mental problems $(19 \%)$, and provide care for more than eight years.

\section{THE WELL-BEING OF INFORMAL CAREGIVERS: EMPIRICAL FINDINGS}

In this section, the estimation results for the two well-being equations are presented. Table II shows the results of the two questions and the two different specifications, i.e. with and without allowing the effect of hours of provided care to depend on the relationship between the informal caregiver and their care recipient. The fact that the questionnaire included two happiness questions (see section 'Survey questions'), allows us to check for consistency. Given that one question is regressed with an ordered categorical model and the other with a linear model, the magnitude of the coefficients cannot be compared between the two questions. The differences can thus only be evaluated in terms of sign and 
Table II. Informal caregivers' well-being

\begin{tabular}{|c|c|c|c|c|c|c|c|c|}
\hline & \multicolumn{4}{|c|}{$\begin{array}{l}\text { Happiness } 1-5 \\
\text { OP }\end{array}$} & \multicolumn{4}{|c|}{$\begin{array}{l}\text { Happiness } 0-10 \\
\text { OLS }\end{array}$} \\
\hline & \multicolumn{2}{|c|}{ Specification 1} & \multicolumn{2}{|c|}{ Specification 2} & \multicolumn{2}{|c|}{ Specification 1} & \multicolumn{2}{|c|}{ Specification 2} \\
\hline & Est. & $z$-value & Est. & $z$-value & Est. & $t$-value & Est. & $t$-value \\
\hline Ln(Hours Informal Care) & -0.248 & -6.070 & -0.243 & -5.920 & -0.390 & -5.070 & -0.382 & -4.960 \\
\hline Ln(Hours Informal Care) $*$ No Family & - & - & 0.107 & 2.410 & - & - & 0.141 & 1.660 \\
\hline Ln(net income per month in Euro) & 0.208 & 2.250 & 0.217 & 2.340 & 0.305 & 1.720 & 0.314 & 1.770 \\
\hline Dummy sex: male & 0.003 & 0.030 & 0.022 & 0.220 & 0.203 & 1.040 & 0.228 & 1.170 \\
\hline Ln(age) & 0.034 & 0.160 & 0.050 & 0.230 & 0.725 & 1.770 & 0.738 & 1.810 \\
\hline Informal caregiver is married & 0.117 & 0.990 & 0.127 & 1.070 & -0.147 & -0.650 & -0.131 & -0.580 \\
\hline Informal caregiver has children & -0.079 & -0.680 & -0.066 & -0.570 & -0.223 & -0.990 & -0.210 & -0.930 \\
\hline Dummy education: low ${ }^{\mathrm{a}}$ & -0.002 & -0.020 & -0.016 & -0.120 & 0.379 & 1.450 & 0.360 & 1.380 \\
\hline Dummy education: middle ${ }^{\mathrm{a}}$ & -0.122 & -1.040 & -0.141 & -1.190 & 0.219 & 0.960 & 0.190 & 0.830 \\
\hline Informal caregiver is unemployed & -0.640 & -1.760 & -0.621 & -1.700 & -0.807 & -1.210 & -0.775 & -1.160 \\
\hline Dummy caregiver has an illness & -0.433 & -4.400 & -0.423 & -4.290 & -0.435 & -2.310 & -0.419 & -2.220 \\
\hline $\begin{array}{l}\text { Dummy care recipient has } \\
\text { mental problems }{ }^{b}\end{array}$ & -0.416 & -3.570 & -0.420 & -3.600 & -0.733 & -3.280 & -0.734 & -3.290 \\
\hline $\begin{array}{l}\text { Dummy care recipient has physical } \\
\text { and mental problems }{ }^{b}\end{array}$ & -0.318 & -3.260 & -0.322 & -3.310 & -0.428 & -2.300 & -0.432 & -2.320 \\
\hline Intercept term 1 & -0.730 & & -0.540 & & 2.494 & 1.200 & 2.283 & 1.100 \\
\hline Intercept term 2 & -0.354 & & -0.163 & & & & & \\
\hline Intercept term 3 & 1.033 & & 1.234 & & & & & \\
\hline Intercept term 4 & 1.790 & & 2.000 & & & & & \\
\hline Number of observations & 662 & & 662 & & 658 & & 658 & \\
\hline Pseudo $R^{2}$ & 0.054 & & 0.057 & & & & & \\
\hline $\operatorname{Adj} . R^{2}$ & & & & & 0.064 & & 0.067 & \\
\hline
\end{tabular}

${ }^{a}$ Reference group: informal caregivers with high education.

${ }^{\mathrm{b}}$ Reference group: care recipients with physical problems.

statistical significance. Focusing only on the statistically significant variables, the results show that the differences in estimation results between both regression techniques are minor.

As expected, there is a negative effect of the hours of provided care on the informal caregiver's wellbeing. This negative effect is smaller if the informal caregiver and the care recipient are no family related. For instance, the estimated negative coefficient of the variable $\ln$ (hours of informal care) on the $1-5$ question is $-0.136(-0.243+0.107)$ if the care recipient and informal caregiver are no family related, and -0.243 if they are family related. The interaction term between 'hours of informal care' and 'family relation with the care recipient' is, however, only statistically significant at $10 \%$ for the $0-10$ happiness question. Net monthly household income has a positive coefficient.

As usual in the literature, having an illness has a negative statistically significant coefficient on wellbeing. The type of illness of the care recipient has also an impact on caregiver's well-being: providing informal care to a person with 'mental' or with 'mental and physical problems' has a statistically significant negative impact on well-being as compared to care recipients with (only) physical problems.

Table II also shows that a fairly large number of coefficients are not statistically significant. Probably, this is due to the present sample specificities. For example, while the age coefficient is usually found to be statistically significant (Van Praag and Ferrer-i-Carbonell, 2004), here age does not show a statistically significant result. The most plausible explanation is that the present sample is fairly old and therefore unable to identify the age effect correctly (lack of heterogeneity). Being married, having children, level of education, and being unemployed are, contrarily to the results presented in Table II, 
usually found to have a statistically significant coefficient on well-being (Van Praag and Ferrer-iCarbonell, 2004). In $49 \%$ of the cases, informal caregivers in the sample are taking care of their own partner. Therefore, one tempting explanation for the not positive coefficient of 'being married' is that the $49 \%$ married caregivers, even if happy to have a partner, perceive his or her presence as an emotional and physical burden. Thus, the positive effects of being married are compensated by the negative effect of having a sick partner. A possible explanation for the non-significant coefficient of having children is that, given the old age of the respondents, most of the children are not living at home and thus have less direct contact with them. The non-statistically significant coefficient for male is usual in the literature, while the non-statistically significant coefficient for unemployment might be due to lack of observations in this relatively small sample.

Next to the presented empirical results we have included other variables in the regression in order to test whether or not they had an impact on our presented results. These include care recipients' income, access to formal support services, more details regarding the informal care tasks (viz. housework, activities of daily living, and instrumental activities of daily living), and the period informal caregivers already provide informal care. Only the years that the informal caregivers already provide informal care were statistically significant and took away most of the direct effect of provided hours of informal care. This variable, however, is strongly correlated with other individual characteristics, such as income (individuals who provide care for many years may have fewer opportunities to have a paid job or a career). Therefore, we decided not to include this variable in our final model.

\section{A MONETARY VALUE OF INFORMAL CARE}

In this section, the results presented in Table II are used to calculate the monetary value of informal care as described in Equations (2), (4) and (5). Later this information will be compared with the values obtained with the contingent valuation method when using the same sample (Van den Berg et al., 2005b).

Table III presents the results when the relationship between the care recipient and the caregiver is not taken into account (specification 1) and Table IV when the relationship is taken into account (specification 2). As explained earlier, the relationship between well-being and both income and hours of provided care is not linear but logarithmic. Therefore, the compensating variation for an extra hour of informal care depends on the current income and on the actual number of hours of provided care. To take this into account, Tables III and IV present the estimates of the value of informal care for various initial numbers of hours given, including the sample average of provided hours of informal care. The income is taken at the sample average.

Table III. Monetary value of informal care, per hour; first specification (in Euros)

\begin{tabular}{|c|c|c|c|c|}
\hline \multirow[b]{2}{*}{ Informal care hours } & \multicolumn{2}{|c|}{ Happiness $1-5$} & \multicolumn{2}{|c|}{ Happiness $0-10$} \\
\hline & $\%$ of current income & Money value $^{\text {a }}$ (Euros/h) & $\%$ of current income & Money value $^{\mathrm{a}}$ (Euros/h) \\
\hline $9-10$ & 13.4 & 51.12 & 14.4 & 55.08 \\
\hline $19-20$ & 6.3 & 24.08 & 6.8 & 25.89 \\
\hline $29-30$ & 4.1 & 15.75 & 4.4 & 16.92 \\
\hline $39-40$ & 3.1 & 11.70 & 3.3 & 12.57 \\
\hline $59-60$ & 2.0 & 7.73 & 2.2 & 8.30 \\
\hline $\begin{array}{l}1 \text { extra hour from average } \\
\text { (Average hours }=49 \text { ) }\end{array}$ & 2.4 & 9.31 & 2.6 & 9.99 \\
\hline
\end{tabular}

${ }^{\mathrm{a}}$ Income is set equal to the sample average. 
Table IV. Monetary value of informal care, per hour; second specification (in Euros)

\begin{tabular}{|c|c|c|c|c|}
\hline \multirow[b]{2}{*}{ Informal care hours } & \multicolumn{2}{|c|}{ Happiness $1-5$} & \multicolumn{2}{|c|}{ Happiness $0-10$} \\
\hline & $\begin{array}{l}\% \text { of current } \\
\text { income }\end{array}$ & $\begin{array}{l}\text { Money value } \\
\quad(\text { Euros } / \mathrm{h})\end{array}$ & $\begin{array}{l}\% \text { of current } \\
\text { income }\end{array}$ & $\begin{array}{l}\text { Money value } \\
\quad \text { (Euros/h) }\end{array}$ \\
\hline \multicolumn{5}{|c|}{ Caregiver is not a family member } \\
\hline $9-10$ & 6.8 & 23.69 & 8.4 & 29.23 \\
\hline $19-20$ & 3.3 & 11.34 & 4.0 & 13.93 \\
\hline $29-30$ & 2.1 & 7.45 & 2.6 & 9.15 \\
\hline $39-40$ & 1.6 & 5.55 & 2.0 & 6.81 \\
\hline $49-50$ & 1.1 & 3.68 & 1.3 & 4.51 \\
\hline \multicolumn{5}{|l|}{$59-60$} \\
\hline $\begin{array}{l}1 \text { extra hour from average } \\
\text { (Average hours }=30 \text { ) }\end{array}$ & 2.1 & 7.21 & 2.5 & 8.84 \\
\hline \multicolumn{5}{|l|}{ Caregiver is a family member } \\
\hline $9-10$ & 12.5 & 48.40 & 13.7 & 52.85 \\
\hline $19-20$ & 5.9 & 22.85 & 6.4 & 24.88 \\
\hline $29-30$ & 3.9 & 14.95 & 4.2 & 16.27 \\
\hline $39-40$ & 2.9 & 11.11 & 3.1 & 12.09 \\
\hline $49-50$ & 1.9 & 7.34 & 2.1 & 7.98 \\
\hline \multicolumn{5}{|l|}{$59-60$} \\
\hline $\begin{array}{l}1 \text { extra hour from average } \\
\text { (Average hours }=52 \text { ) }\end{array}$ & 2.2 & 8.33 & 2.3 & 9.06 \\
\hline
\end{tabular}

${ }^{\mathrm{a}}$ Income is set equal to the sample average of each group.

The sample average of hours of provided informal care is 49 per week. At this average, caregivers would need an income compensation of about $2.5 \%$ of their current income to maintain a constant wellbeing after providing one extra hour of informal care per week. Given the average caregiver income, this equals about 9.3 or 10 Euros per hour (depending on the well-being question used). In other words, at the average income and number of informal care hours provided, the value of an extra hour is about 9.3 or 10 Euros.

Table III also shows that, when the number of hours provided increases, the average value of each hour decreases. For example, the value of each hour of informal care for a caregiver who provides $29 \mathrm{~h}$ of informal care per week is about 16 or 17 Euros. This value, however, is about 24 or 26 Euros per hour if the caregiver provides $19 \mathrm{~h}$ of informal care.

Table IV presents the results when the effect of the hours of provided informal care on well-being is allowed to depend on the relationship between the caregiver and the care recipient. Comparing the value of an extra hour of informal care for the two groups is not straightforward, as several aspects influence the final value. First, the coefficient of hours of informal care is larger for family members than for nonfamily members (see Table II). This means that, at every given number of provided hours of informal care and level of income, providing care involves a larger well-being loss for family than for non-family members.

Second, the translation from percentages of income to absolute money values depends on the current income. Given that the income of the family-related caregivers is, on average, slightly higher, the difference between the two monetary values (in absolute terms) of the two samples for every hour of informal care becomes larger.

Third, the monetary value of an additional hour of informal care depends on how many hours the caregiver is already providing. The value of each extra hour of provided informal care decreases considerably as the number of hours provided of care increase. The caregivers who are family related with their care recipient provide, on average, many more hours of care than the caregivers who are not family related with their care recipient. On average, family members provide $52 \mathrm{~h}$ of care a week, while 
non-family members provide $30 \mathrm{~h}$. This means that the monetary value of an extra hour of provided care to family members gets reduced if we take into account the average hours provided.

The final result is that, at the average income and hours of provided informal care, the monetary compensation for an extra hour of care provided to family members is very similar to the one for nonfamily members. When using question 1 (well-being rated 1-5), it is about 8 Euros for family members and 7 Euros for non-family members and when using question 2 (well-being is rated from 0-10), it is about 9 Euros for both family and non-family members. In both cases, the similitude between the two subgroups of caregivers is due to the fact that the average of provided hours of care is much larger for family-related caregivers.

As earlier discussed, it is important to keep in mind that the hours of informal care provided to family members could be over reported. Caregivers who live in the same household as the care recipient may tend to over report their hours by counting as informal care activities that usually would fall under the normal household activities. Van den Berg et al. (2006) tested, in two other samples, whether there was over reporting on the hours of provided care. Their results point at a redistribution of time spent on housework tasks (e.g. house maintenance seems to be sacrificed in order to clean and cook), as well as at over reporting. However, their study did not distinguish between family and non-family-related respondents.

\section{THE WELL-BEING VALUATION METHOD COMPARED WITH CONTINGENT VALUATION}

This section compares the results of the well-being valuation method with the ones found with a contingent valuation study based on the same data set. This makes the comparison very interesting. The contingent valuation questions were posed in the form of informal caregivers' WTA in order to provide an additional hour of informal care per week (Van den Berg et al., 2005b,c). Table V presents this comparison. In doing so, we have again used two specifications: specification 1 estimates the monetary value for all informal caregivers together; specification 2 separated them depending on whether or not caregivers are family related to their care recipients.

In the present case, the contingent valuation method can provide two values depending on whether or not the informal caregiver and the care recipient are family related. This is possible because, in the present survey, caregivers were asked to take into account their current situation when answering the WTA question (see Van den Berg et al., 2005b). Alternatively, the WTA question could provide a description about the care recipient, for example, regarding of whether or not it is a family-related person. This would be necessary if the survey would have been carried on a sample from the general population that had no (necessarily) experience with providing informal care.

Table $\mathrm{V}$ shows that the well-being valuation method gives, through all specifications, a lower monetary value of informal care giving than contingent valuation. The differences between the wellbeing valuation method and the contingent valuation method are statistically significant for all the values except for the difference between the 0 and 10 happiness questions for non-family members with the $\mathrm{CV}$ for non-family members. ${ }^{9}$ The difference in required compensation between family and nonfamily caregivers is small and not statistically significant neither for the subjective well-being valuation method nor for the contingent valuation method.

\footnotetext{
${ }^{9}$ These differences are calculated by correcting for the standard error of the differences. The standard errors of the monetary values for the well-being valuation method are obtained from STATA using the command for non-linear combinations of coefficients. For the contingent valuation method, the standard error is calculated from the distribution of the WTA values as reported by the individuals.
} 
Table V. Mean compensation with contingent valuation and well-being valuation methods

\begin{tabular}{|c|c|c|c|}
\hline & $\begin{array}{l}\text { Contingent } \\
\text { valuation }\end{array}$ & $\begin{array}{l}\text { Well-being valuation } \\
\text { (Happiness 1-5) }\end{array}$ & $\begin{array}{l}\text { Well-being valuation } \\
\text { (Happiness } 0-10)\end{array}$ \\
\hline \multicolumn{4}{|l|}{ Specification 1} \\
\hline \multirow[t]{3}{*}{ All caregivers } & $10.52 \mathrm{Euros} / \mathrm{h}$ & 9.31 Euros/h & 9.99 Euros/h \\
\hline & or & or & or \\
\hline & $3.3 \%$ of income & $2.4 \%$ of income & $2.6 \%$ of income \\
\hline \multicolumn{4}{|l|}{ Specification 2} \\
\hline \multirow[t]{3}{*}{ Family-related caregivers } & 10.64 Euros/h & 8.33 Euros/h & 9.06 Euros/h \\
\hline & & & or \\
\hline & $3.1 \%$ of income & $2.2 \%$ of income & $2.3 \%$ of income \\
\hline \multirow[t]{3}{*}{ Non-family-related caregivers } & 9.44 Euros/h & 7.21 Euros/h & 8.84 Euros/h \\
\hline & & & \\
\hline & $3.3 \%$ of income & $2.1 \%$ of income & $2.5 \%$ of income \\
\hline
\end{tabular}

\section{DISCUSSION AND CONCLUSION}

This paper has shown that it is possible to find a monetary value for informal care based on the impact that providing care has on individual's well-being. The latter is measured by means of a self-reported subjective happiness question. This method considers all costs (and benefits) that providing informal care has on individual's well-being (utility). Valuing informal care is of importance if we aim at capturing all costs in economic evaluations of health care.

The monetary value of informal care using the well-being valuation method is found as follows. First, individual's well-being is econometrically estimated so as to see the effect of hours of provided care and of income on individual's well-being, when controlling for other individual characteristics. Second, the monetary value of informal care is estimated by calculating the income necessary to bring individuals to their original well-being after providing an extra hour of informal care. Thus, the value of informal care is found by calculating the compensating variation.

The empirical results showed that it is useful to distinguish caregivers depending on whether or not the care recipient is family related to the caregiver. In particular, we find that for every given hour of care, providing care to family members involves a larger loss of utility than providing care to non-family members. We postulate that this may be due to the emotional involvement with the care recipient. Caregivers providing care to family-related care recipients, provide, on average, much more hours of care a week than the other caregivers. This, together with the postulated empirical specification that the monetary value of informal care decreases with the number of provided hours of care, leads to the result that when looking at the value of an extra hour of provided care, the difference between the two groups gets much reduced and it is statistically not significant.

The monetary value found when using the well-being valuation method is about the market price for professional home care (7-10 Euro/h versus 8.53 Euro/h) (Van den Berg, 2005). In the Netherlands, the tariff for specialised home care is much higher: 32.67 Euro/h. The well-being valuation method also gives smaller monetary values than the usually recommended opportunity cost method. For instance, using the opportunity cost method, Van den Berg et al. (2006) report values of 17.34 and 10.64 Euro/h for providing care to stroke and rheumatoid arthritis care recipients, respectively. When using the proxy good method in the same samples, they find values of 13.51 and 12.19 Euro/h, respectively. The smaller amount found with the well-being valuation method compared with the market value (proxy good method) and the opportunity cost method probably illustrates that the market values do not take into account all the costs and benefits associated with providing informal care. This result seems to indicate that the ignored benefits in the market value weigh more than the ignored costs. It seems that informal 
caregivers, by caring for a family or acquaintance (friends or neighbours), derive positive utility from the process of caring itself (process utility or direct utility).

The contingent valuation method should also be able to capture the total costs and effects associated with providing informal care. Van den Berg et al. $(2005 \mathrm{~b}, \mathrm{c})$ showed that this method seems to be able to account for the associated morbidity risks of providing informal care. However, Van den Berg et al. (2005c) showed that this seems not to hold for issues related to the subjective aspects of providing informal care, viz. the emotional evolvement. These authors concluded that this might be due to multicollinearity. Nevertheless, it can also be that respondents do not take these aspects into account when answering contingent valuation questions. The fact that contingent valuation does not capture the subjective effects of providing care may explain the higher values found with the contingent valuation method as compared to the well-being valuation method. One way to assure that contingent valuation captures also the subjective aspects may be to ask contingent valuation questions for hypothetical care recipients instead of for actual care recipients. This issue should be solved in future research. Another explanation for the higher value found when using contingent valuation methods could be that people use the value of market alternatives as an anchor value when answering contingent valuation questions. Van Exel et al. (2006) pointed at anchoring in case of contingent valuation applied to informal caregiving. A final and more classical explanation for the higher values obtained with contingent valuation is strategic bias. The WTA questions were framed in the form of a hypothetical governmental compensation for providing extra informal care (Van den Berg et al., 2005b,c). This might have induced strategic answering. Although in this context no reimbursement decisions are made based on informal caregivers' answers, it could be that respondents think that their answers influence policy. Anecdotic evidence regarding strategic bias is that one of the authors received a few months after the data collection an email from one of the respondents with the phrase: 'I thought we would get money from the government for our caregiving activities. I have not received any money yet. Could you please advise me on how I can get it?'

By being able to capture all the costs and benefits associated with providing informal care, the well-being valuation method provides a good alternative to value non-market goods in health economics. Another good property of this method is the easiness of response. The percentage of individuals who do not respond to well-being valuation questions is very low (Van Praag and Ferrer-iCarbonell, 2004). In the present sample, only 2.5-3.4\% (depending on the question used) of the informal caregivers failed to answer the well-being questions. This contrasts with the percentage of informal caregivers who failed to answer the contingent valuation questions (42.8-49.8\% depending on the questions used). ${ }^{10}$ Similarly, answering conjoint analysis questions requires a considerable effort from the respondent. This could especially be the case when the vignettes include many attributes or when attributes contain elements that the respondent is not familiar with (Ryan and Gerard, 2003; Van Ophem et al., 1999).

The empirical results of the well-being valuation method show the usefulness of the method for the health economics literature in general and more particularly for the economic valuation of informal care. The well-being valuation method is not superior to the more traditional methods of contingent valuation or conjoint analysis. It is, however, a useful complement which gives an additional possibility to determine the convergent validity of the different valuation methods (Clarke, 2002; Van den Berg, 2005). Moreover, the well-being valuation method might be cheaper to implement, as answering the well-being question requires less time and less survey space than answering the other valuation

\footnotetext{
${ }^{10}$ It is worth noting that the non-response on contingent valuation questions depends heavily on the choice format used. The present questionnaire consisted of open-ended questions, which are the most difficult for respondents to answer (Green et al., 1998). In another questionnaire, Van den Berg et al. (2005c) used a dichotomous choice contingent valuation question with an open follow-up question to value informal care. They report a non-response of $19 \%$, which is still much higher than the nonresponse rate of the happiness questions.
} 
questions. Moreover, there are already data available from large national surveys, such as the GSOEP, the BHPS and the Household, Income and Labour Dynamics in Australia (HILDA), which can be used to test and validate the well-being valuation method. These data could fill a gap in the current knowledge, especially when more detailed studies and questionnaires are lacking. Next to providing a monetary value of informal care, this study highlighted the conceptual and empirical differences between different valuation methods. The well-being valuation method gives the research community and policy makers a new, additional, and flexible economic valuation instrument.

\section{ACKNOWLEDGEMENTS}

A previous draft of this paper was presented at the 5th World Congress of the international Health Economics Association (iHEA) in Barcelona, at the 26th Australian Conference of Health Economists in Auckland and at the Netherlands Bureau for Economic Policy Analysis. We like to thank the participants of these three sessions for their comments and discussion. We would also like to thank Gregory Jolivet, Wien Limburg and two anonymous referees for very useful comments.

\section{REFERENCES}

Blanchflower D, Oswald AJ. 2004. Well-being over time in Britain and the USA. Journal of Public Economics 88: 1359-1386. DOI:10.1016/S0047-2727(02)00168-8

Boyle KJ, Holmes TP, Teisl MF, Roe B. 2001. A comparison of conjoint analysis response formats. American Journal of Agricultural Economics 83: 441-454. DOI:10.1111/0002-9092.00168

Brouwer WBF, Van Exel JAJ, Van den Berg B, Van den Bos GAM, Koopmanschap MA. 2005. Process utility from providing informal care: the benefit of caring. Health Policy 74: 85-99. DOI:10.1016/j.healthpol.2004.12.008

CBS: Statline. http://www.cbs.nl/nl-NL/menu/cijfers/statline/toegang/default.htm [14 July 2006].

Clark AE, Oswald AJ. 1994. Unhappiness and unemployment. Economic Journal 104: 648-659. DOI:10.2307/ 2234639

Clarke PM. 2002. Testing the convergent validity of the contingent valuation and travel cost methods in valuing the benefits of health care. Health Economics 11: 117-127. DOI:10.1002/hec.651

DiTella R, MacCulloch RJ, Oswald AJ. 2001. Preferences over inflation and unemployment: evidence from surveys of subjective well-being. American Economic Review 91: 335-341.

Drummond MF, O'Brien BJ, Stoddart GL, Torrance GW. 1997. Methods for the Economic Evaluation of Health Care Programmes (2nd edn). Oxford University Press: Oxford.

Easterlin RA. 2001. Income and happiness: towards a unified theory. Economic Journal 111: 465-484. DOI:10.1111/ 1468-0297.00646

Ferrer-i-Carbonell A. 2005. Income and well-being: an empirical analysis of the comparison income effect. Journal of Public Economics 89: 997-1019. DOI:10.1016/j.jpubeco.2004.06.003

Ferrer-i-Carbonell A, Frijters P. 2004. How important is methodology for the estimates of the determinants of happiness? Economic Journal 114: 641-659. DOI:10.1111/j.1468-0297.2004.00235.x

Ferrer-i-Carbonell A, Van Praag BMS. 2002. The subjective costs of health losses due to chronic diseases. An alternative model for monetary appraisal. Health Economics 11: 709-722. DOI:10.1002/hec.696

Ferrer-i-Carbonell A, Van Praag BMS, Theodossiou I. 2006. Image and reality: the case of job satisfaction. Working Paper, University of Amsterdam, Amsterdam.

Frey BS, Stutzer A. 1999. Measuring preferences by subjective well-being. Journal of Institutional Theoretical Economics 155: 755-778.

Frey B, Stutzer A. 2002. What can economists learn from happiness research? Journal of Economics Literature 40: 402-435. DOI: $10.1257 / 002205102320161320$

Frijters P, Haisken-DeNew JP, Shields MA. 2004. Money does matter! Evidence from increasing real incomes and life satisfaction in East Germany following reunification. American Economic Review 94: 730-740. DOI:10.1257/ 0002828041464551 
Green D, Jacowitz KE, Kahneman D, McFadden D. 1998. Referendum contingent valuation, anchoring, and willingness to pay for public goods. Resource and Energy Economics 20: 85-116. DOI:10.1016/S09287655(97)00031-6

Hughes SL, Giobbie-Hurder A, Weaver FM, Kubal JD, Henderson W. 1999. Relationship between caregiver burden and health-related quality of life. Gerontologist 39: 534-545.

Jacobi CE, Van den Berg B, Boshuizen HC, Rupp I, Dinant HJ, Van den Bos GAM. 2003. Dimension-specific burden of caregiving among partners of rheumatoid arthritis patients. Rheumatology 42: 1-8.

Johannesson M, Borgquist L. 1991. Willingness to pay for antihypertensive therapy - results of a Swedish pilot study. Journal of Health Economics 10: 461-473. DOI:10.1016/0167-6296(91)90025-I

Johannesson M, Johansson PO, Kriström B, Gerdtham UG. 1993. Willingness to pay for antihypertensive therapy - further results. Journal of Health Economics 12: 95-108. DOI:10.1016/0167-6296(93)90042-D

Kramer BJ. 1997. Gain in the caregiving experience: where are we? What next? Gerontologist 37: $218-232$.

Louviere J, Hensher D, Swait J. 2000. Conjoint preference elicitation methods in the broader context of random utility theory preference elicitation methods. In Conjoint Measurement: Methods and Applications, Gustafsson A, Herrmann A, Huber F (eds). Springer: Berlin; 279-318.

Luce BR, Wanning WG, Siegel JE, Lipscomb J. 1996. Estimating costs in cost-effectiveness analysis. In CostEffectiveness in Health and Medicine, Gold MR, Siegel JE, Russell LB, Weinstein MC (eds). Oxford University Press: New York; 176-213.

Luttmer EFP. 2005. Neighbors as negatives: relative earnings and well-being. Quarterly Journal of Economics 37: 218-232. DOI:10.1162/003355305774268255

Maddala GS. 1983. Limited Dependent and Qualitative Variables in Econometrics. Cambridge University Press: Cambridge, UK.

Mitchell RC, Carson RT. 1989. Using Surveys to Value Public Goods: The Contingent Valuation Method. Resources for the Future: New York.

Netten A. 1990. An Approach to Costing Informal Care. DP 637. University of Kent: Canterbury.

Norton EC. 2000. Long-term care. In Handbook of Health Economics, Culyer AJ, Newhouse JP (eds). Elsevier: Amsterdam; 955-994.

Oswald AJ. 1997. Happiness and economic performance. Economic Journal 107: 1815-1831. DOI: 10.1002/hec.1107

Posnett J, Jan S. 1996. Indirect cost in economic evaluation: the opportunity cost of unpaid inputs. Health Economics 5: 13-23. DOI: 10.1002/(SICI)1099-1050(199601)5:1<13::AID-HEC182>3.0.CO;2-J

Roe B, Boyle KJ, Teisl MF. 1996. Using conjoint analysis to derive estimates of compensating variation. Journal of Environmental Economics Management 31: 145-159. DOI:10.1006/jeem.1996.0037

Russell LB, Siegel JE, Daniels N, Gold MR, Luce BR, Mandelblatt JS. 1996. Cost-effectiveness analysis as a guide to resource allocation in health: roles and limitations. In Cost-Effectiveness in Health and Medicine, Gold MR, Siegel JE, Russell LB, Weinstein MC (eds). Oxford University Press: New York; 3-24.

Ryan M, Gerard K. 2003. Using choice experiments to value health care programs: current practice and future research reflections. Applied Health Economics and Health Policy 2: 55-64.

Stone PW, Chapman RH, Sandberg EA, Liljas B, Neumann PJ. 2000. Measuring costs in cost-utility analyses: variations in the literature. International Journal of Technology Assessment in Health Care 16: 111-124. DOI.org/ $10.1017 / \mathrm{S} 0266462300161100$

Timmermans JM. 2003. Mantelzorg. Over de Hulp van en aan Mantelzorgers [in Dutch]. SCP: Den Haag.

Van den Berg B. 2005. Informal Care: An Economic Approach. Thesis, Erasmus University Rotterdam, Rotterdam.

Van den Berg B, Al MJ, Brouwer WBF, Van Exel JAJ, Koopmanschap MA. 2005a. Economic valuation of informal care: the conjoint measurement method applied to informal caregiving. Social Science and Medicine 61: 1342-1355. DOI:10.1016/j.socscimed.2005.01.029

Van den Berg B, Bleichrodt H, Eeckhoudt L. 2005b. The economic value of informal care: a study of informal caregivers' and patients' willingness to pay and willingness to accept for informal care. Health Economics 14: 363-376. DOI:10.1002/hec.980

Van den Berg B, Brouwer WBF, Koopmanschap MA. 2004. Economic valuation of informal care: an overview of methods and applications. European Journal of Health Economics 5: 36-45. DOI:10.1007/s10198-003-0189-y

Van den Berg B, Brouwer WBF, Van Exel JAJ, Koopmanschap MA. 2005c. Economic valuation of informal care: the contingent valuation method applied to informal caregiving. Health Economics 14: 169-183. DOI:10.1002/hec.893

Van den Berg B, Brouwer WBF, Van Exel JAJ, Koopmanschap MA, Van den Bos GAM, Rutten FFH. 2006. Economic valuation of informal care: lessons from the application of the opportunity costs and proxy good methods. Social Science and Medicine 62: 835-845. DOI:10.1016/j.socscimed.2005.07.001

Van den Berg B, Spauwen P. 2006. Measurement of informal care: an empirical study into the valid measurement of time spent on informal caregiving. Health Economics 15: 447-460. DOI:10.1002/hec.1075 
Van Exel JAJ, Brouwer WBF, Van den Berg B, Koopmanschap MA. 2006. With a little help from an anchor: evidence of anchoring in contingent valuation of informal caregiver time inputs. Journal of Socio-Economics $\mathbf{3 5}$ : 836-853.

Van Ophem H, Stam P, Van Praag BMS. 1999. Multichoice logit: modelling incomplete preference rankings of classical concerts. Journal of Business and Economic Statistics 17: 117-128. DOI:10.2307/1392243

Van Praag BMS, Baarsma BE. 2005. Using happiness surveys to value intangibles: the case of airport noise. Economic Journal 115: 224-246. DOI:10.1111/j.1468-0297.2004.00967.x

Van Praag BMS, Ferrer-i-Carbonell A. 2004. Happiness Quantified. A Satisfaction Calculus Approach. Oxford University Press: Oxford. 